\title{
Effect of process parameters on mechanical properties of AA5052 joints using underwater friction stir welding
}

\author{
D. Paramaguru1', S. R. Pedapati1* M. Awang ${ }^{1}$, H. Mohebbi ${ }^{1}$, K. V. Sharma² \\ 1 Universiti Teknologi PETRONAS, Bandar Seri Iskandar 32610, Malaysia. Phone: +605 368 7207; Fax: +605 3656461 \\ 2 JNTU College of Engineering, JNT University Hyderabad, India
}

\begin{abstract}
Underwater Friction Stir Welding (UFSW) is a solid-state joining technique which uses a non-consumable tool to weld metals. The objective of this investigation is to evaluate the mechanical properties of the AA5052 Aluminium alloy joints prepared by UFSW. The effect of different type of welding tools and welding parameters on the weld joint properties are studied. Square, tapered cylindrical and taper threaded cylindrical type of welding tools have been used to produce the joints with the tool rotational speed varying from $500 \mathrm{rpm}$ to $2000 \mathrm{rpm}$ while the welding speed varying from $50 \mathrm{~mm} / \mathrm{min}$ to $150 \mathrm{~mm} / \mathrm{min}$. Tensile strength, micro-hardness distribution, fracture features, micro-and macrostructure of the fabricated weld joints have been evaluated. The effect of welding process parameters that influences the mechanical properties and fracture characterization of the joints are explained in detail. A maximum Ultimate Tensile Strength (UTS) value of $222.07 \mathrm{MPa}$ is attained with a gauge elongation of $14.78 \%$. Microstructural evaluation revealed that most of the fracture are found on the thermal mechanically affected zone (TMAZ)adjacent to the weld nugget zone (WNZ) due to bigger grain sizes. It is found that most of the joints exhibit ductile characteristics in failure. Fractography analysis has been used to find the behavior of weld joints in failure.
\end{abstract}

ARTICLE HISTORY

Revised: $7^{\text {th }}$ Sept 2019

Accepted: $18^{\text {th }}$ Sept 2019

\section{KEYWORDS}

Underwater FSW;

heat affected zone;

joint strength;

microstructure;

Aluminium alloy.

\section{INTRODUCTION}

AA5052 aluminum alloys are one of the high strength alloys which comprises magnesium as its leading alloying element. This material is principally well-suited for shipbuilding and marine applications, for instance marine components, fuel tanks and oil lines, by virtue of its outstanding peculiarity in resistance to corrosion. It is extensively used for the superstructures and building of ships to develop the above waterline size of the vessel without creating stability problems. The light weight advantage of AA5052 correspondingly has gain much attention in construction of other marine architectures as well [1]. Friction stir welding (FSW) is a solid state joining process that has been extensively applied in joining aluminum alloys. It is also notable for its low welding distortion and low production cost, as well as high welding quality. Despite the fact that, thermal cycles can still create undesirable consequences on mechanical properties of weld joints through FSW of precipitated hardened aluminum alloys. This is caused by the coarsening of the strengthening precipitates. The FSW also does not dissolve the base material (BM) since it is generated under lower heat input. The coarsening of strengthening precipitates that is generated by thermal cycles of FSW tends to create weld nugget zone (WNZ), heat affected zone (HAZ), and thermal mechanically affected zone (TMAZ) which are generally named as soften region. This degradation of mechanical properties in aluminium alloy is primarily impacts weld joint's HAZ, and this remains as a crucial issue in the field of welding. As result of the mentioned deterioration process, the tensile strength of the stir zone (SZ) also decreases from BM [2]. Therefore, it is necessary to improve the joint properties of aluminium alloys by controlling the temperature level of welding process. Accordingly, water is preferred as a great cooling medium especially for aluminium alloys during the FSW process. It is better known as Underwater Friction Stir Welding (UFSW) [3].

An ultimate improvement on tensile strength was proven with water cooling effect in the FSW of AA7075-T6 places that substantially lessen the soften zones and improved the joint properties [4]. UFSW is capable to enhance the joint's mechanical properties compared to the normal FSW while reduced residual stress and generated minimum thermal cycle curve [5]. By narrowing the precipitate free zone and shortening the hardened level, the hardness of the Heat Affected zone (HAZ) can be enhanced. The refinement in the mechanical properties and microstructures in the Heat Affected Zone (HAZ) and differences in welding thermal distribution is due to the water cooling treatment. This welding culture is comprehensively supported to diminish several welding defects or imperfections such as splatter, embrittlement, porosity, cracking, shrinkage, solidification and etcetera [6,7]. These researches revealed that higher rotational speed can yield good quality welds owing to the outstanding thermal capacity of water, increased cooling rate and reduced peak temperature. A maximum micro-hardness value was determined in the stir zone with improved elongation of the joint. In the present investigation, the effect of various process parameters on AA5052 Aluminium alloy joints made of UFSW has been studied. 


\section{MATERIALS AND METHODS}

Material

The material used in the present study is 5052 aluminum alloy plates with rectangular cross section of size $150 \mathrm{~mm}$ (length) $\times 100 \mathrm{~mm}$ (width) $\times 6 \mathrm{~mm}$ (thickness). This material carries UTS value of $228 \mathrm{MPa}$ with elongation of $12 \%$.

\section{Process Parameters}

The range of welding speed and tool rotational speed used for this study are $50 \mathrm{~mm} / \mathrm{min}$ to $150 \mathrm{~mm} / \mathrm{min}$, and $500 \mathrm{rpm}$ to $2000 \mathrm{rpm}$ respectively. Aluminium alloy plates are welded using three different welding tools; square, tapered cylindrical and taper threaded cylindrical. These welding tools were manufactured using chromium hot-worked H-13 tool steel material and carries machinability rate of nearly $75 \%$ of the $\mathrm{W}$-group tool steels [8]. Figure 1 shows the welding tools utilized in this study and the tool dimensions are shown in Table 1.

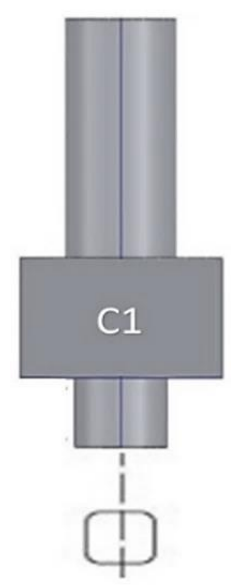

Square

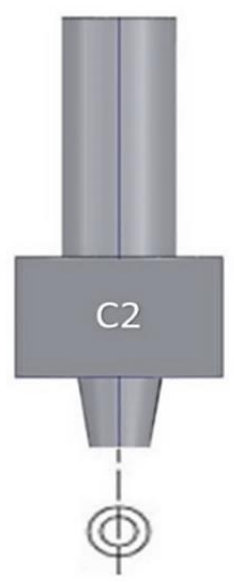

Tapered Cylindrical

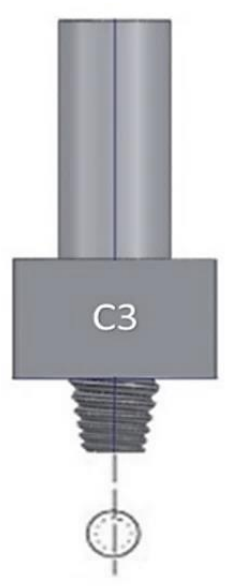

Taper Threaded Cylindrical

Figure 1. Type of tools used for underwater friction stir welding: Square (C1), Tapered Cylindrical (C2), Taper Threaded Cylindrical (C3)

Table 1. Welding tools dimensions.

\begin{tabular}{ccc}
\hline Type of FSW Tool & $\begin{array}{c}\text { Shoulder Diameter } \\
\text { (millimeter) }\end{array}$ & Diameter of Pin (millimeter) \\
\hline Square $\left(\mathrm{C}_{1}\right)$ & 28.1 & $\begin{array}{c}7.8 \\
\text { (Length-5.5mm) } \\
7.8 \& 4.2\end{array}$ \\
Tapered Cylindrical $\left(\mathrm{C}_{2}\right)$ & 28.1 & $\begin{array}{c}7 \text { Length-5.5mm) } \\
7.8 \& 4.2\end{array}$ \\
$\begin{array}{c}\text { Taper Threaded Cylindrical } \\
\left(\mathrm{C}_{3}\right)\end{array}$ & 28.1 & (Length-5.5mm) \\
\hline
\end{tabular}

\section{Design of Experiments and Experimental Procedure}

This experiment examined the prospective effects of three parameters and its three levels on the response variable. The effect of parameters is defined as the changes in the response variable for certain levels of parameter values. The selection of parameters level values on the experimental unit is controlled by the weld joint quality. The parameters levels can be qualitative or quantitative. Quantitative parameters are usually constructed from ordered numerical values, while qualitative parameters are described by continuous variables. A full-factorial Design of Experiment (DoE) have been employed to lead an equal number of replicates of all possible combinations of parameters levels. This statistical DoE is used to plan the number of experiments for finite response in terms of UTS values and the process parameters (or variables). In present study, a full-factorial experimental design (three parameters with three levels for each parameter) is expressed as a $3 \times 3 \times 3=3^{3}$ design, making a total of 27 runs [9]. The response was the ultimate tensile strength (UTS) of the joint.The factors and the selected levels of UFSW process parameters are listed in Table 2. 
Table 2. Process parameters for UFSW.

\begin{tabular}{lcccc}
\hline Parameters/ Units & Notation & \multicolumn{3}{c}{ Factor Levels } \\
\hline $\begin{array}{l}\text { Tool Rotational Speed } \\
(\mathrm{rpm})\end{array}$ & $\mathbf{A}$ & 500 & 1500 & 2000 \\
Welding Speed & & $\left(A_{1}\right)$ & $\left(A_{2}\right)$ & $\left(A_{3}\right)$ \\
(mm/min) & $\mathbf{B}$ & 50 & 100 & 150 \\
Type of welding Tool & $\mathbf{C}$ & $\left(B_{1}\right)$ & $\left(B_{2}\right)$ & $\left(B_{3}\right)$ \\
& & $\left(C_{1}\right)$ & Tapered Cylindrical & Taper threaded \\
& & & $\left(C_{2}\right)$ & $\left(C_{3}\right)$ \\
\hline
\end{tabular}

The workpieces were cleaned with acetone thoroughly to remove any dirt, fine particles and organic material. Then rigidly clamped using the mechanical backing plate to ensure a strong contact while positioning the workpieces to be welded. Water with room temperature was filled into tank to submerge the upper layer of the workpiece, as shown in Figure 2. FSW Machining Centre (namely, FSW-TS-F16) was used to perform welding, which is capable to control the desired process parameters and ensured repeatability. Butt weld was carried out laterally on the workpiece by counterclockwise rotation of welding tool.

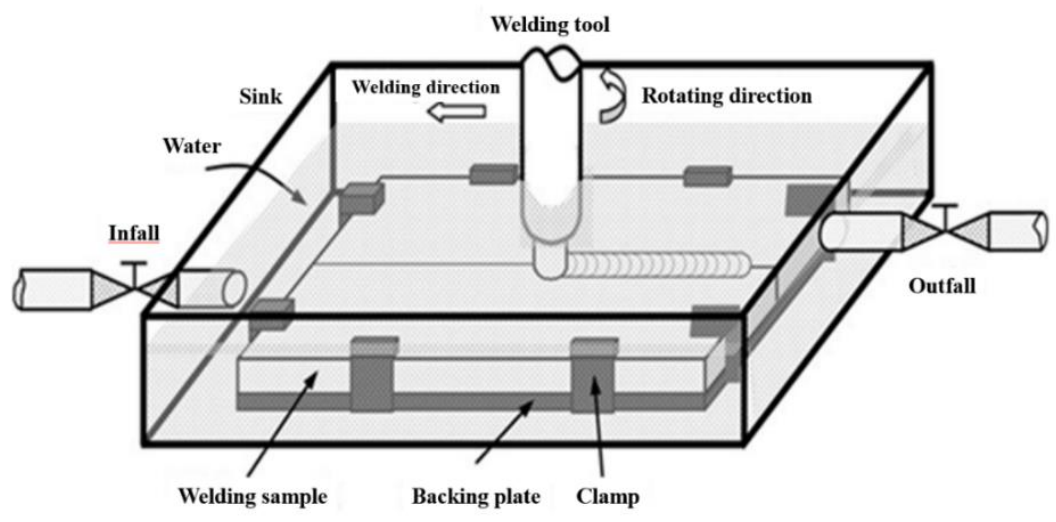

Figure 2. Schematic setup of underwater friction stir welding.

Electrical-Discharge Cutting Machine has been used to cut the specimens from the welded joints, Vickers's microhardness test and metallographic analysis of the different welding parameters. For tensile test, the configuration and size of the welded tensile specimens were prepared with reference to American Society for Testing of Materials (ASTM) E8M-04 standard [10]. The tensile specimen's dimension is illustrated in Figure 3. After tensile test, a Scanning Electron Microscopy was employed to examine the fracture features of the joints that portrayed maximum and minimum UTS values. The Vickers's micro-hardness (HV) test was used with spacing between indents of $1 \mathrm{~mm}$ and a load of $4.9 \mathrm{~N}$ for 10 seconds. Metallographic analysis to study the microstructural features of the workpieces were accomplished using an optical microscope. The metallographic specimen's cross-sections were ground, refined and etched for 10 to 60 seconds using a solution composed of $25 \mathrm{ml}$, Methanol $\left(\mathrm{CH}_{3} \mathrm{OH}\right), 25 \mathrm{ml}$ Hydrochloric acid $(\mathrm{HCl}), 25 \mathrm{ml} \mathrm{Nitric}$ acid $\left(\mathrm{HNO}_{3}\right)$ and a drop of Hydrofluoric acid (HF) [11].

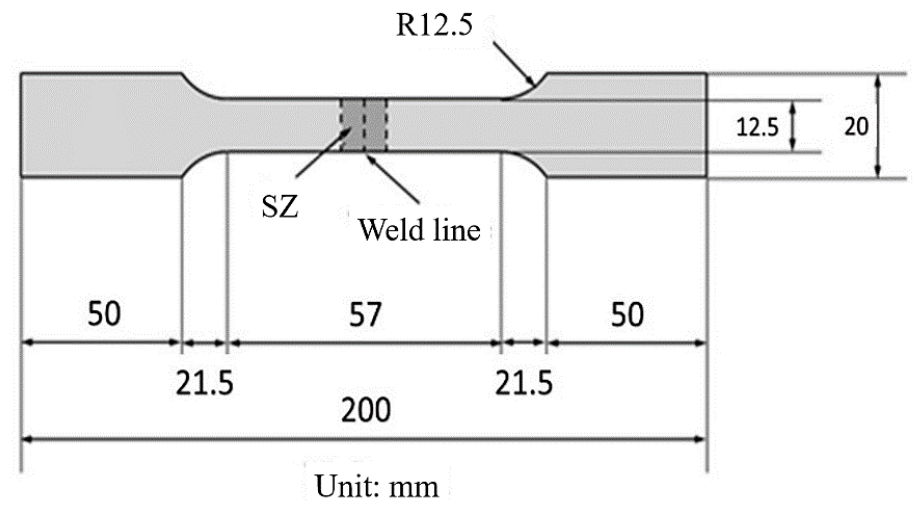

Figure 3. Tensile test specimen as per ASTM E18M-04 standard [10]. 


\section{RESULTS AND DISCUSSION}

\section{Tensile Properties}

Tensile properties of a welded joint significantly rely upon its welding process parameters. Figure 4 and Figure 5 show the Ultimate Tensile Strength (UTS) and elongation at each process parameters, respectively. A maximum UTS value of $222.07 \mathrm{MPa}$ was attained from the process parameter of A2B1C3 (1500rpm, $50 \mathrm{~mm} / \mathrm{min}$, Taper threaded cylindrical tool). The welded joint efficiency correspondingly (defined as the ratio of the weld joint UTS to that of the base material) achieved $97.4 \%$ of the base material (BM). The BM exhibits UTS of $228 \mathrm{MPa}$. The degree of ductility of the weld joint can be determined by the percentage of elongation value. The joint ductility appears to tail the similar behavior as the tensile strength, and the plateau gauge elongation is $14.78 \%$ which is greater than of the BM (12\%). Such a result pointed out that the tensile properties of the joint are able to be enhanced extremely by UFSW technique. But, overcooling does not increase much on its elongation as a result of lower heat generation of the weld region that entail hardening of the weld joint. Still, it is greater than that of the BM and better ductility was achieved.

To make a comparison, FSW experiment in normal condition (in air) using process parameter of A2B1C3 was conducted. It was identified that the UTS and elongation value of the normal joint were $204.80 \mathrm{MPa}(89.8 \%$ of the BM) and $13.12 \%$, respectively. The outcomes for the tensile testing of UFSW workpiece was disclosed to be greater than the results obtained by normal FSW. The UTS and elongation value obtained by UFSW is about $8.43 \%$ and $1.66 \%$, correspondingly higher than that of the normal FSW joint, further confirming the positive effect of water cooling on strength enhancement. What is more, the process parameter of A2B2C3 too fabricated good indication of mechanical properties in UFSW where the UTS value is comparable (218.24 MPa) and resulted in good ductility with elongation of $13.35 \%$. Submerging workpieces in water exaggerated the mechanical properties of the UFSW material. It is exclusively related to the heat input and the ensuing microstructure that were formed to be affected by submerging in water medium [12]. As predicted, water promises a greater cooling medium and, in this way, a good enhancement is achieved in UTS and elongation of the welded joints.

On the other hand, the lowest UTS value was made by tapered cylindrical tool (C2) with tool rotational speed and tool welding speed of $500 \mathrm{rpm}$ and $150 \mathrm{~mm} / \mathrm{min}$, correspondingly. In simple words, it is A1B3C2 process parameter. An elongation of $6.69 \%$ was obtained while facilitates low heat generation and restricted tool stirring time at lower tool rotational speed and higher tool welding speed. It was apparent that, the elongation increased dramatically using $\mathrm{C} 2$ tool with increasing tool rotational speeds and tool welding speeds except for the case of $\mathrm{A} 3 \mathrm{~B} 2 \mathrm{C} 2$ and $\mathrm{A} 3 \mathrm{~B} 3 \mathrm{C} 2$, at which a decrease of elongation took place due to excessive heat generation and fast tool movement. A maximum elongation of $13.49 \%$ was performed by A3B1C2 process parameter with UTS of $162.72 \mathrm{MPa}$ by C2 tool. Still, both the tensile properties of this tool are lower compared to maximum tensile properties obtained by $\mathrm{C} 3$ tool.

During tensile test, the plastic deformation was primarily focused on the softening region of the weld. The average micro-hardness profile of this tool as well exhibited increment with the increase of tool rotational speed and tool welding speed owing to an enhancement in plastic deformation capability of the joint. Yet, it is also aided to increase the strain hardening capacity of the WNZ. The synergetic effects of this factor permit the elongation not to change appreciably from $\mathrm{A} 1 \mathrm{~B} 1 \mathrm{C} 2$ to $\mathrm{A} 2 \mathrm{~B} 2 \mathrm{C} 2$. By the same token, the elongations featured by the squared tool $(\mathrm{C} 1)$ did not remarkably presented good results. The elongations performed by this tool were lower than of the BM, which owed to low fracture toughness, equiaxed grains and the presence of precipitate free zones. The microstructural grain growth by means of heat input plays a significant role in the mechanical properties of the weld joint. Irrespective of the process parameters, the enhancement of the tensile properties for the welded joint is interrelated with the effect of external water-cooling action on the coarsening process. An adequate heat input and good amount of cooling rate was directed to less grain growth, and as a result, finer grain structure and enhanced mechanical properties. The micro structural characteristics of the weld joint elucidates in detail the intrinsic reasons for this variance.

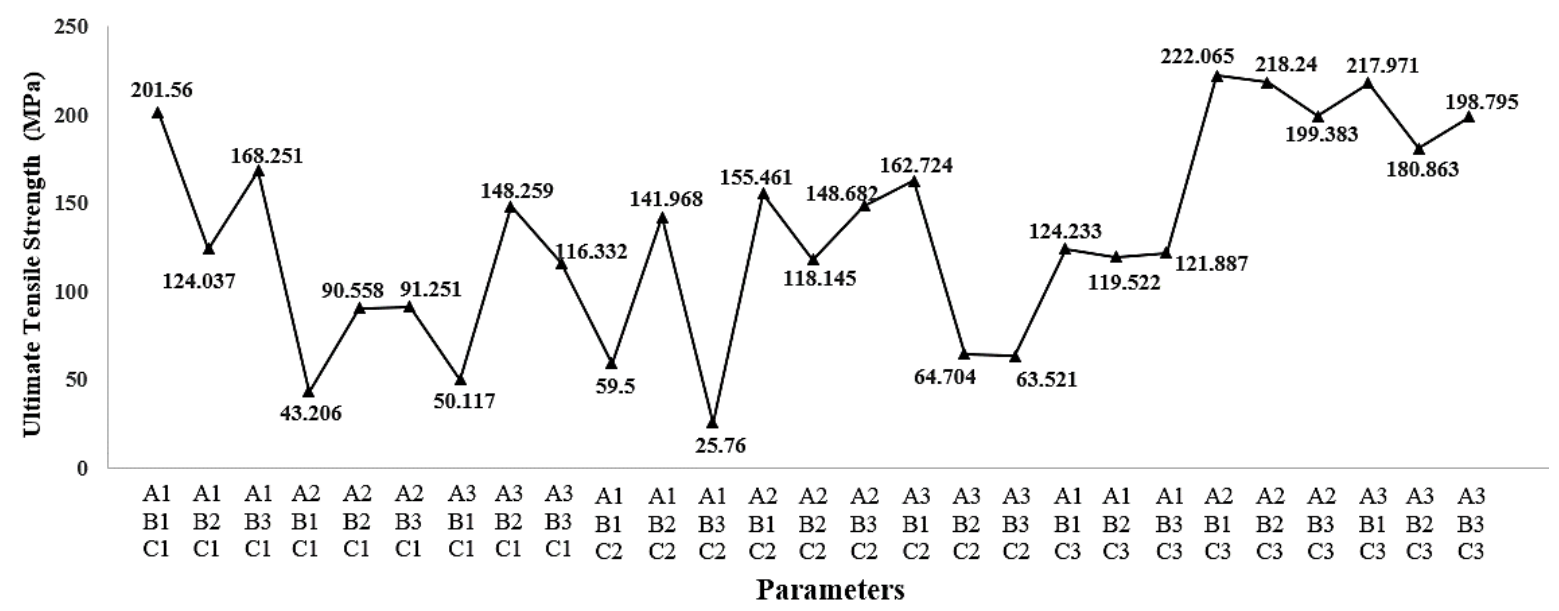

Figure 4. Ultimate tensile strength of joints made at each combination of process parameters. 


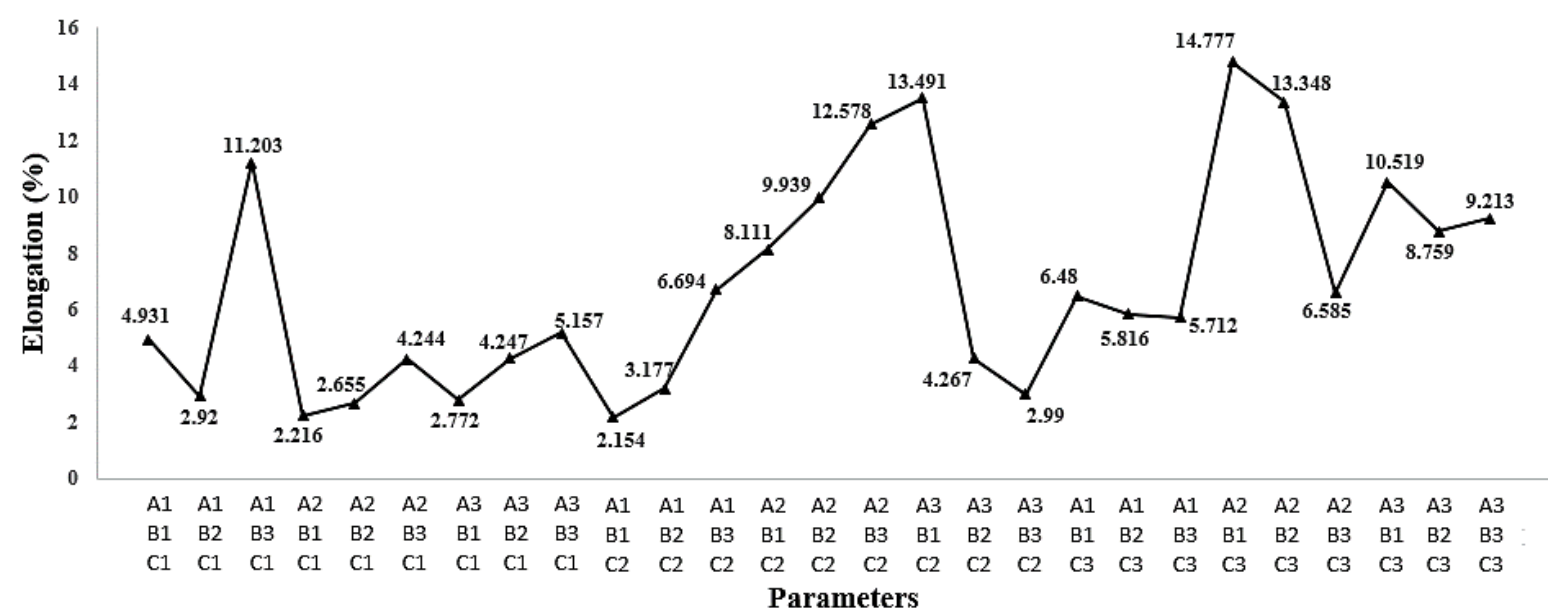

Figure 5. Elongation of joints at each combination of process parameters.

Thus, the tool rotational speed and tool welding speed as well as the type of welding tool must be chosen in an appropriate range to fabricate great joint quality in UFSW technique. Typically, the present exploration proved that too low or too high tool rotational speeds and tool welding speeds can both generate poor joint properties. The former is attributed to the insufficient tool stirring effect and the latter is endorsed to the extreme heat input. Subsequently, a proper process parameter is required so the strain hardening caused by tool stirring can efficiently advance the mechanical properties of the weld joint. And so forth, the heat input will neither extremely weaken the mechanical properties of the stir zone nor led to welding defects on the joints [13]. When the tool welding speed and tool rotational speeds were within a certain critical value in regards with the type of welding tool, the UFSW was able to fabricate defect-free joints. If the tool welding speed and tool rotational speed were beyond the critical value, welding defects were formed in the joints and acted as a preferential crack initiation spot during tensile test. The tensile properties and fracture locations of the joints were noticeably reliant on the welding defects and micro-hardness distributions of the joints. If a joint is free of defects, the tensile properties of the joint is only reliant on the micro-hardness distributions of the joint. The fracture locations of the weld joints vary in accordance to different process parameters, such as on AS, RS and WNZ. This infers that the tensile properties of the joints are not similar on the both sides of the weld center. Despite the fact that, the UFSW joint is an inhomogeneous composite and its dissimilar component parts comprising of its interfaces carries dissimilar mechanical properties.

\section{Microhardness Distributions}

The measured hardness values of different joints are presented in Figure 6, Figure 7 and Figure 8, which are categorized based on type of welding tool for better comparison of the tool geometry. The 5052 aluminium alloy presented an uneven distribution of micro-hardness values throughout the weld line, besides yielded greater value of hardness at the stirred zone (SZ) of the joint compared to the base material (BM). These results are confirmed to the research findings published by $[14,15]$. The maximum hardness values are present on the intermediate of the SZ attributed to the effect of generated welding thermal cycles of the joint which is the pertinent factor inducing the local material micro-hardness values. Lower hardness values are found on the TMAZ next to the WNZ, except on process parameters of $A_{1} B_{1} C_{3}, A_{1} B_{2} C_{3}$ and $\mathrm{A}_{1} \mathrm{~B}_{3} \mathrm{C}_{3}$ which is due to increasing precipitate weakening level at the WNZ of the joint. To be exact, lowest hardness region of the joint moves towards the center of the weld on lower range of tool rotational speed using taper threaded cylindrical tool. It is because of inadequate amount of material flow and heat is attained during the welding process. Still, the micro hardness values in this region are marginally higher than when compared to all the regions. Moreover, the HAZ in UFSW joints are much narrowed because of decreased influence of welding thermal cycles on welded joint thru watercooling effect of this experiment. This condition is directly aided to improve the mechanical properties of the weld. All these features are affected by higher cooling rate in this study which conferred to limit as much as possible the thermal flow nearby the tool that effects the weld joint.

It is recorded that the maximum value of hardness as $300 \mathrm{HV}$ is yielded by parameters $\mathrm{A}_{2} \mathrm{~B}_{1} \mathrm{C}_{3}(1500 \mathrm{rpm}, 50 \mathrm{~mm} / \mathrm{min}$, taper threaded cylindrical tool) which obtained in the middle of the SZ, near advancing side (AS), is remarkably four times higher than that of its BM. It is because of reduced impact of thermal cycles of welding on the properties of welding joint thru assist of high cooling rate and intense deformation which produced smaller grain sizes. In contrast, the minimum value of hardness is yield by $\mathrm{A}_{1} \mathrm{~B}_{3} \mathrm{C}_{2}(500 \mathrm{rpm}, 150 \mathrm{~mm} / \mathrm{min}$, tapered cylindrical tool) which is $50.5 \mathrm{HV}$ at retreating side (RS) of the joint which attributed to larger grain sizes. It is evident that micro-hardness value is significantly correlated to the size of grain, and the grains encounter greater growth with escalating heat input which consequently led to lower micro-hardness. The interdependence between the strength and the grain size is acknowledged after the Hall-Petch relation. It implies that the strength or hardness is inversely proportionally to the average size of grain. Except parameters of $A_{2} B_{1} C_{1}, A_{1} B_{1} C_{2}, A_{1} B_{2} C_{2}, A_{2} B_{1} C_{2}, A_{2} B_{2} C_{2}$ and $A_{1} B_{1} C_{3}$, it is shown that most of the fracture happened at $R S$ of the weld due to restricted tensile strain in the thermo-mechanically affected zone (TMAZ) of both sides of weld one. The 
strength influence by the grain refinement differs with region to region of the welded joint. The TMAZ exhibits the bigger grain sizes and consequently it produced low hardness values. It is fractured at or adjacent to the minimum hardness value of the joint correspondingly at each process parameters combinations. Therefore, it can be concluded that, mechanical properties of UFSW joints are influenced by the strain localization region.

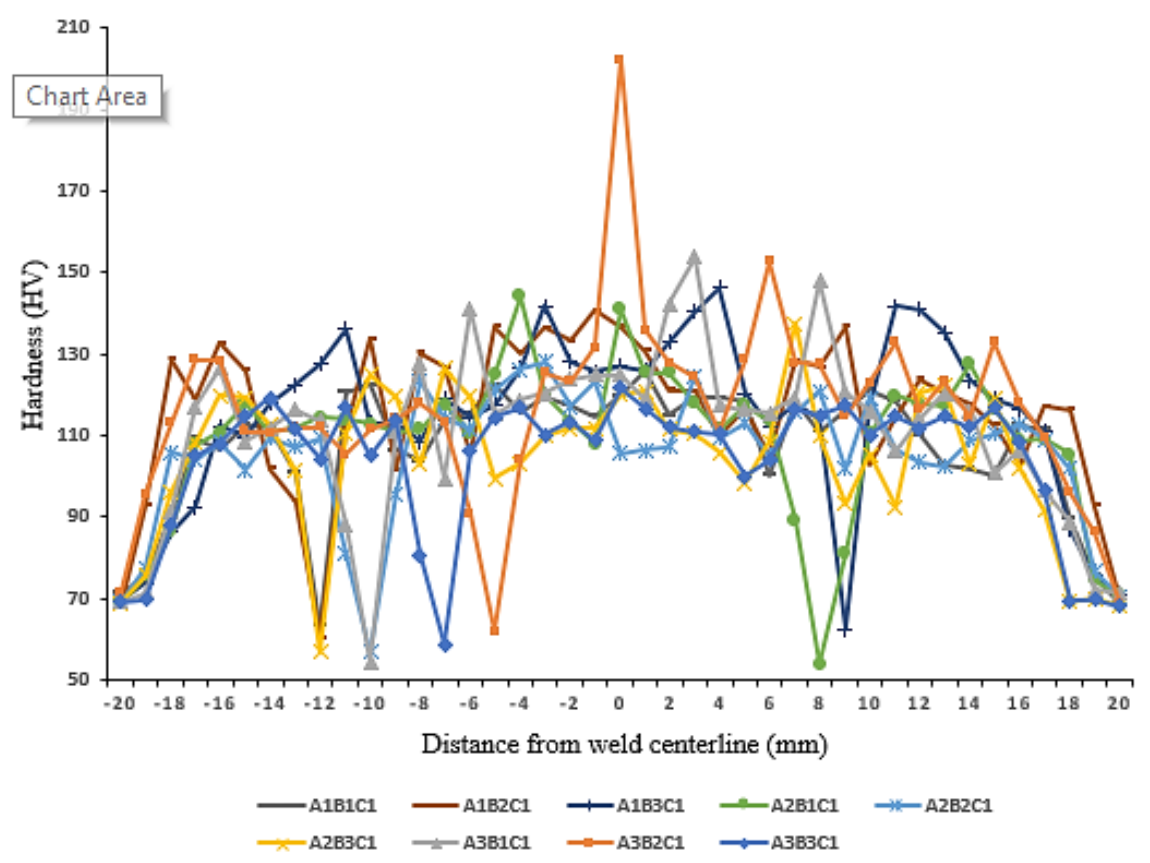

Figure 6. Distributions of microhardness in different joints made by square tool $\left(\mathrm{C}_{1}\right)$.

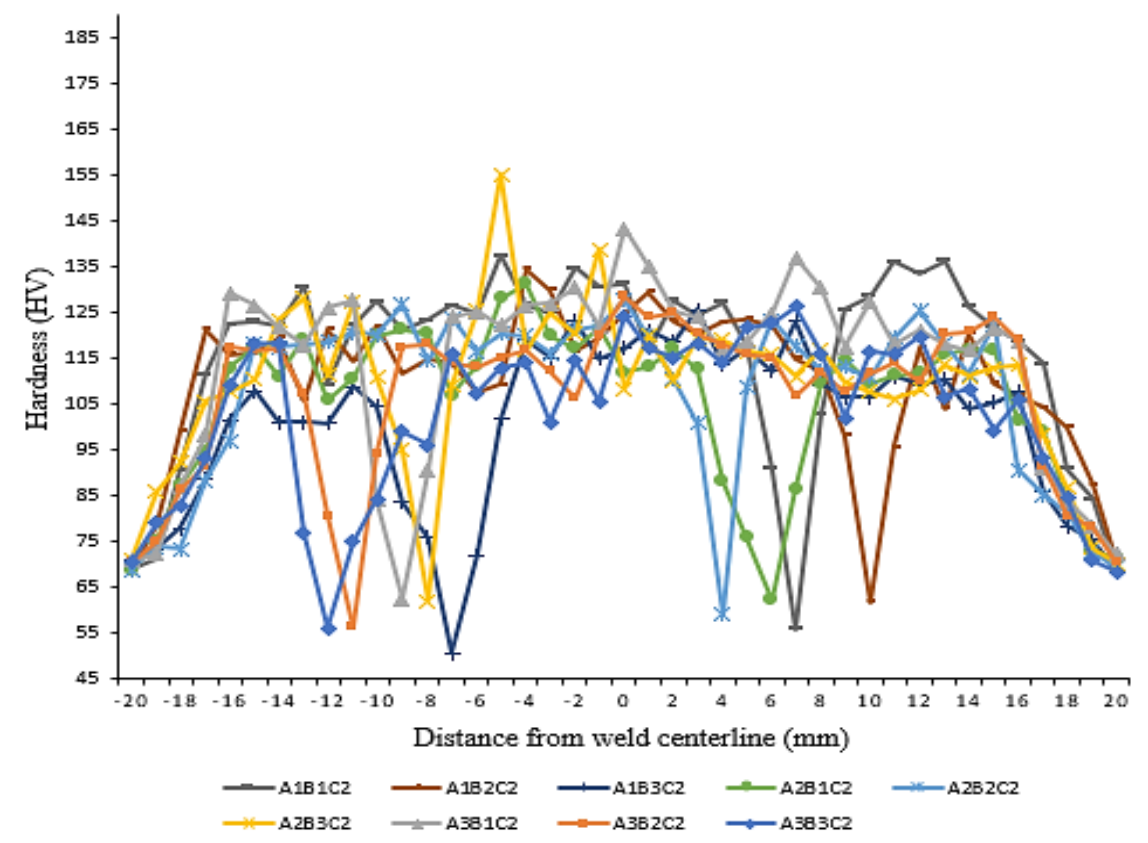

Figure 7. Distributions of microhardness in different joints made by tapered cylindrical tool $\left(\mathrm{C}_{2}\right)$ 


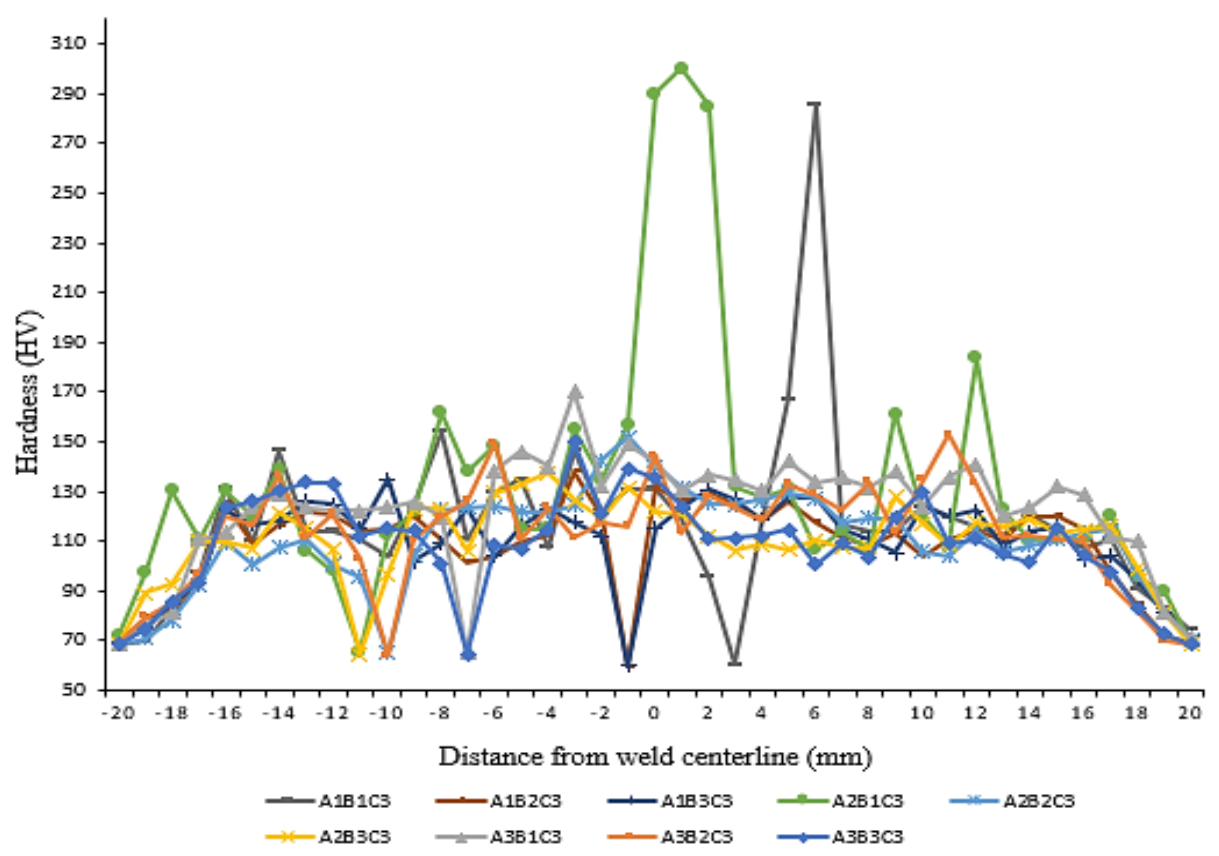

Figure 8. Distributions of Micro hardness in different joints made by Threaded cylindrical tool $\left(\mathrm{C}_{3}\right)$.

It is also observed that the joint hardness on the AS is greater compared to the RS, in most conditions. It is during tool rotation speed as an influential factor where great amount of frictional force and shear force leads to higher temperature exposure in RS compared to AS. The difference in hardness value is happens attributed to metallurgical characteristics by solidification and temperature variance. Those weld joints that fractured at $A S\left(A_{2} B_{1} C_{1}, A_{1} B_{1} C_{2}, A_{1} B_{2} C_{2}, A_{2} B_{1} C_{2}\right.$, $A_{2} B_{2} C_{2}$ and $A_{1} B_{1} C_{3}$ ) are exposed to insufficient amount of material flow and heat is attained by lower tool welding speed and presented poor hardness value. Regardless of SZ, it is comprising of fine grains with huge amount of grain boundaries through intense plastic deformation and high temperatures. Micro structural characteristics of the weld joint explains in detail the grain boundaries differences. Therefore, the SZ has greater micro-hardness value than other regions of this aluminium alloy.

\section{Microstructure}

The tensile properties and micro-hardness value are relying mainly on the microstructural features of the joint. It is predominantly affected by heat generation which reliant upon the process parameters applied. Figure 9 , Figure 10 and Figure 11 shows the optical micrographs of UFSW using square tool $\left(\mathrm{C}_{1}\right)$, tapered cylindrical tool $\left(\mathrm{C}_{2}\right)$ and taper threaded cylindrical tool $\left(\mathrm{C}_{3}\right)$, respectively. The determined grain size in the fabricated joints proved the phenomena happening in the various zones. The typical microstructural regions, such as base material (BM), heat-affected zone (HAZ) and thermomechanically affected zone (TMAZ) are discovered. Moving towards the weld line, firstly, the BM is detected where it is a part of the weld with no grain's deformation since not metallurgically affected by the welding process. It is positioned far from the weld and the microstructure remained unaffected during the entire welding process. Then, in HAZ, not much substantial grain coarsening is noticed. Almost all the weld joints yield grain size which like the grain size of base material. The grains experienced a significant coarsening by short of any deformation with considerable thermal exposure and absence of material deformation. The cooling effect of water affects the microstructural appearance by minimized heat affected zone and heat input. It resulted in considerable increase the tensile properties and micro-hardness value in UFSW technique. The Thermo-Mechanically Affected Zone micrographs are explained by the deformed grains and upward oriented.

A sharper interface between the TMAZ and the WNZ is created as the grains are dragged towards the WNZ greatly. In TMAZ micrographs of joints made using $C_{1}$ tool, the parameter condition of $A_{1} B_{1} C_{1}$ weld joint formed smaller grain size, while the parameter condition of $\mathrm{A}_{3} \mathrm{~B}_{3} \mathrm{C}_{1}$ weld joint yielded larger grain size. In TMAZ micrographs of joints using $C_{2}$ tool, the weld joint of $A_{1} B_{3} C_{2}$ fabricated larger grain size and the weld joint of $A_{3} B_{1} C_{2}$ featured smaller sized grain. Furthermore, larger and smaller grain size were exhibited by the weld join of $A_{3} B_{3} C_{3}$ and $A_{1} B_{3} C_{3}$ parameter conditions. Due to insufficient amount of thermal exposure and material deformation, recrystallization of grain is absent in the TMAZ of UFSW joints. The weld nugget zone (WNZ) micrographs are designated by the existence of fine grains and dynamic recrystallized grains. The weld joint of $\mathrm{A}_{3} \mathrm{~B}_{3} \mathrm{C}_{1}$ parameter condition exhibited larger grain size by $\mathrm{C}_{1}$ tool. Similarly, the $C_{2}$ and $C_{3}$ tools also produced larger grain size in WNZ micrographs of $A_{1} B_{3} C_{2}$ and $A_{3} B_{1} C_{3}$ parameter conditions, respectively. The recrystallized grains are formed due to the synergetic consequence of large thermal exposure and great material deformation in the WNZ that cause the recrystallization development [16,17]. Hence, fine and equiaxed recrystallized grains are formed in the WNZ which is much smaller than in BM. Compared to other tools, $\mathrm{C}_{3}$ tool can produce very fine grains. Simultaneously, great amounts of micro-hardness values are portrayed in WNZ of most process 
parameter conditions. Hence, the refined grain structures and improved solid solution strengthening synthetically result in higher micro-hardness of weld joint and thus increased the tensile strength of UFSW joint.

The microstructural features vary extensively with changes in tool rotational speed and traverse speed, besides the type of welding tool. With tools $\mathrm{C}_{1}$ and $\mathrm{C}_{3}$, the grain size increases along with the increment in tool rotational speed. A clear increment in the grain size of WNZ and TMAZ were identified by these welding tools. At higher tool rotational speed, the weld joints experienced great amount of heat input that led to form large grain size in these zones and increased the strain and strain rate, while resulting inferior tensile properties. It also caused defect formations. Meanwhile, at low tool rotational speed condition, larger grain size is presented, and small grain size is presented in high tool rotational speed condition using $\mathrm{C}_{2}$ tool. It is also implied notably higher tensile values at higher range of tool rotational speed. Simultaneously, it is important to notice that increase in traverse speed influenced to decrease in heat generation and the degree of material deformation.

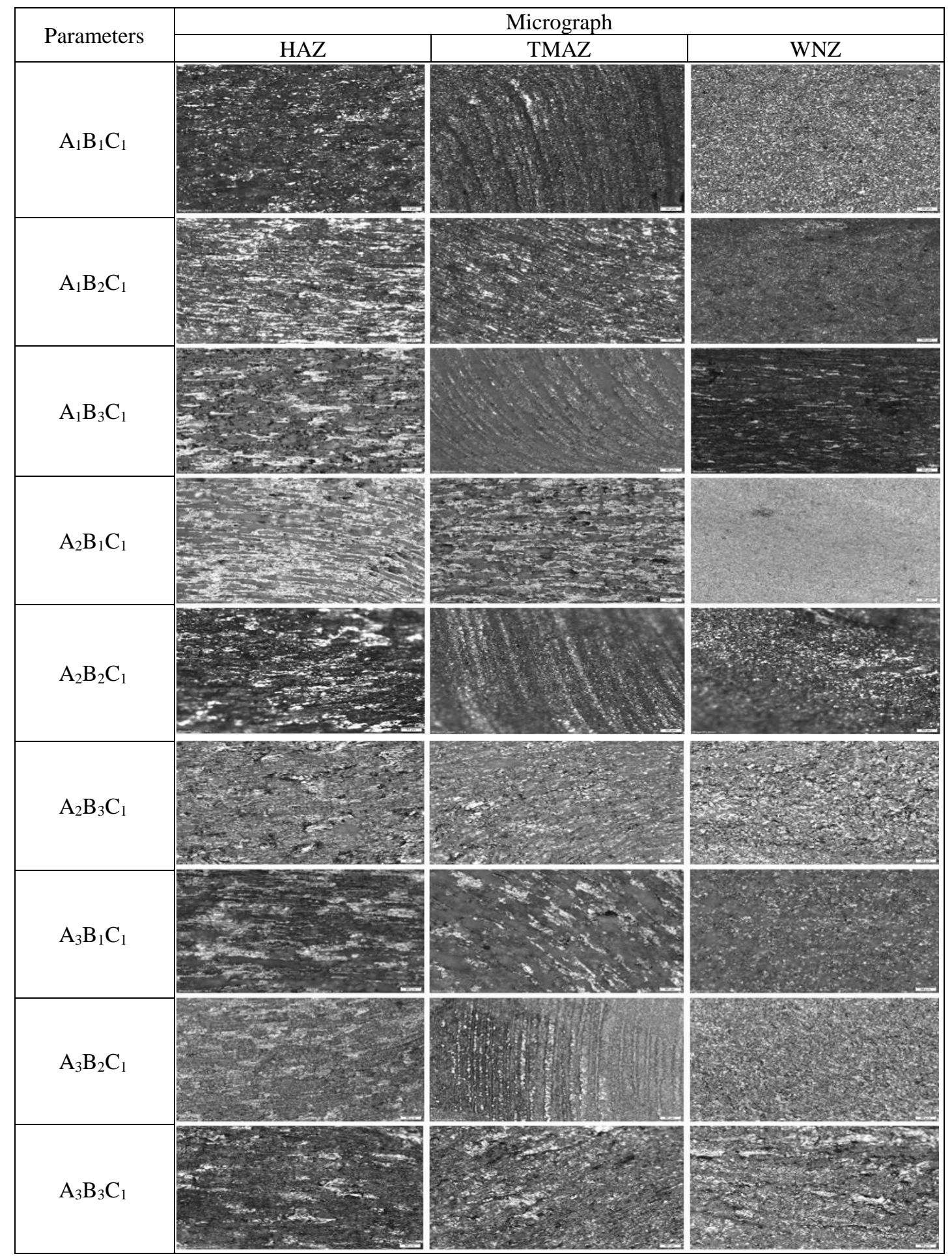

Figure 9. Optical micrographs of UFSW joints made by square tool $\left(\mathrm{C}_{1}\right)$. 


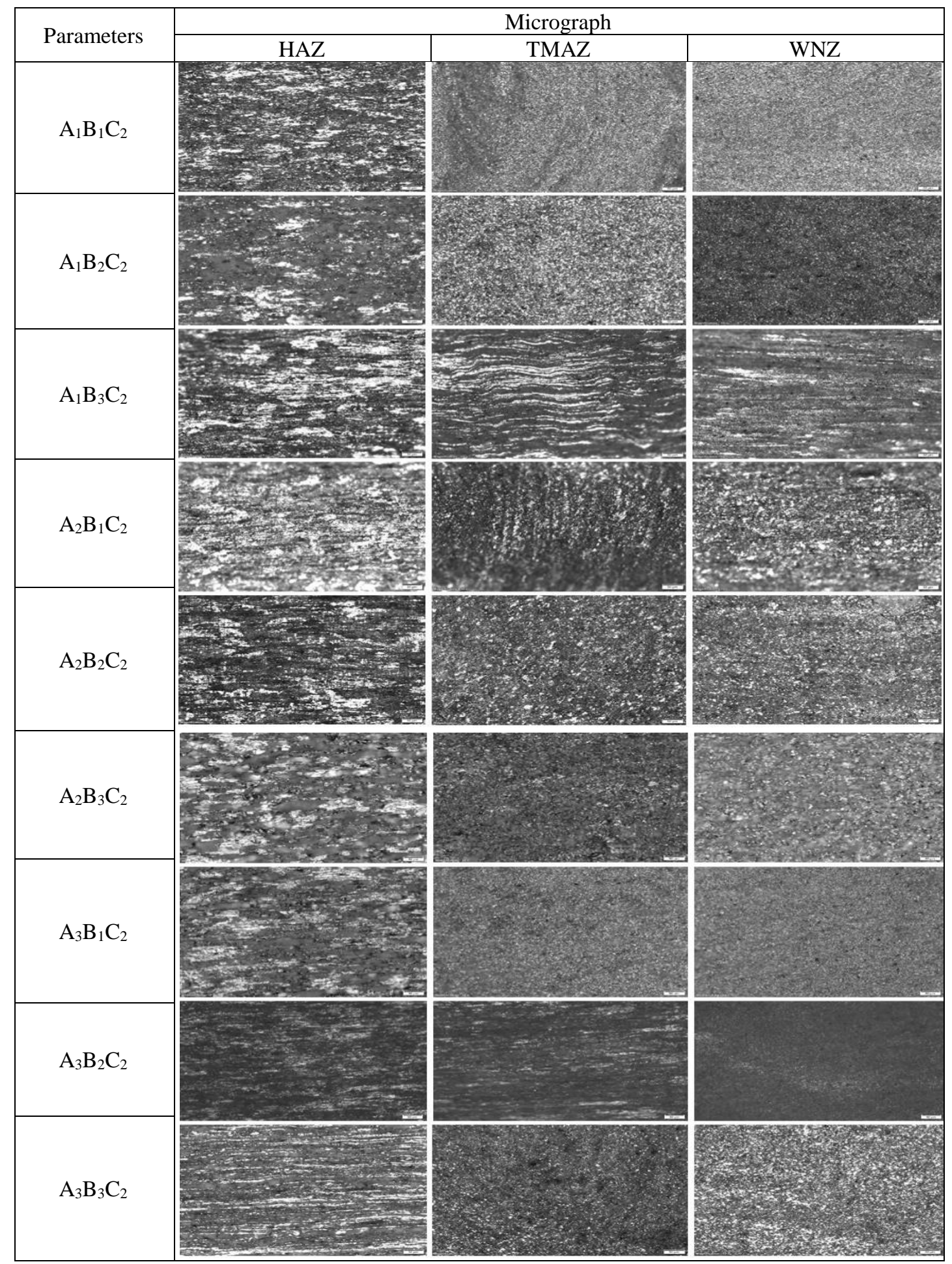

Figure 10. Optical micrographs of UFSW joints made by tapered cylindrical tool $\left(\mathrm{C}_{2}\right)$. 


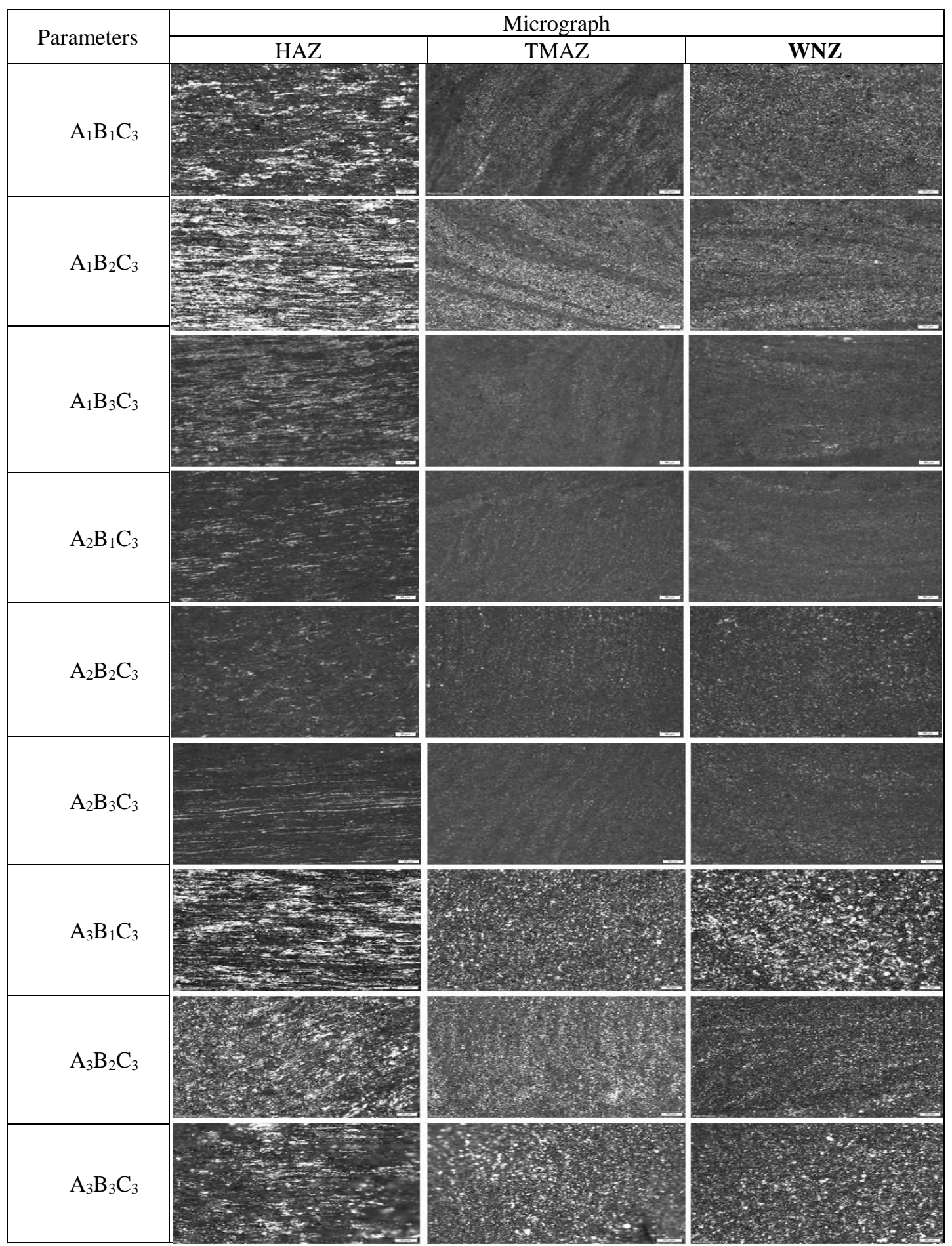

Figure 11. Optical micrographs of UFSW joints made by taper threaded cylindrical tool $\left(\mathrm{C}_{3}\right)$.

This trend is common in most of the joint conditions with regards of type of welding tool. The tensile properties decrease considerably when the tool welding speed is increased. Therefore, the difference in grain size with tool rotational speed and tool welding speed directed by the characteristic of dominant. Thus, an appropriate range of tool rotational speed and tool welding speed are required to produce optimum (balanced) state of material flow and heat generation to fabricate defect free UFSW joints, in regards with type of welding tools. It is also determined that the grain size in UFSW is dominant by the heat input and the material deformation with $\mathrm{C}_{1}$ tool. Comparably, the material deformation dominated the grain size thru $\mathrm{C}_{2}$ tool, and the heat input dominated the grain size thru $\mathrm{C}_{3}$ tool. Consequently, the boundary between the WNZ and the TMAZ is clearly noticeable and turned into a weaker location in the joint. In the weld joints of $\mathrm{A}_{1} \mathrm{~B}_{1} \mathrm{C}_{3}$, $\mathrm{A}_{1} \mathrm{~B}_{2} \mathrm{C}_{3}$ and $\mathrm{A}_{1} \mathrm{~B}_{3} \mathrm{C}_{3}$ process parameters, the $\mathrm{S}$ weld defect takes place on the weld center (WNZ) due to poor interface by inadequate amount of material flow and heat attained during lower range of tool rotational speed. And, the tensile fracture happened at this location. The fracture location associated with poor hardness value of the micro-hardness plot. The micro-hardness and tensile strength imply similar noticeable trends. Besides that, it is also determined that the joint 
hardness on the AS is greater than in the RS, in most conditions. It is because the tool rotation speed which induced huge amount of frictional force and shear force that leads to higher temperature exposure in RS compared to AS. It also attributed to metallurgical characteristics by solidification and temperature variance. Those weld joints that fractured at AS $\left(A_{2} B_{1} C_{1}, A_{1} B_{1} C_{2}, A_{1} B_{2} C_{2}, A_{2} B_{1} C_{2}, A_{2} B_{2} C_{2}\right.$ and $\left.A_{1} B_{1} C_{3}\right)$ are exposed to insufficient amount of material flow and heat attained by lower tool welding speed.

During tensile test, it is equally vital to note that the plastic deformation, particularly on the necking stage, is solely focused in the poor hardness location of the joint [18]. This phenomenon is known as stress and strain localization. For that reason, the elongation value (ductile properties) is mainly identified by the latent plastic deformation capability of the weakest hardness location of the joint. A poor plastic deformation is caused by great density dislocations and narrowing of the soften region. Reduction in elongation that remarkably lower than the $\mathrm{BM}$ is happened in some process parameter conditions of this study. However, the weld joints of $A_{2} B_{3} C_{2}, A_{3} B_{1} C_{2}, A_{2} B_{1} C_{3}$ and $A_{2} B_{2} C_{3}$ yielded elongation greater than the base material. In general, UFSW is clearly able to achieve more grain refinement. The lower the heat input and time the stirring tool spent on the weld joint, the smaller the grain size, which leads to increase the tensile properties and micro-hardness results [19-22].

\section{Fractography Analysis}

Fractography is the analysis of the fracture surface of materials and exerted to identify the reason of failure in weld joints. Figure 12 illustrates the fracture surface analysis of weld joints that portrayed maximum and minimum UTS values. The maximum and minimum UTS values are presented by weld joints of $\mathrm{A}_{2} \mathrm{~B}_{1} \mathrm{C}_{3}$ and $\mathrm{A}_{1} \mathrm{~B}_{3} \mathrm{C}_{2}$ process parameters, respectively. In both the joints, at the macro level fracture surface, two dissimilar forms of rupture patterns are detected. Explicitly, irregular surface is detected at the shoulder dominated region and flat surface is detected at the pin dominated region. Fracture surfaces also expressed that the fracture mode is in solo-shearing in both joints which is the mechanism behind the failure of joint. The SEM pictures (X 5000) illuminated the fracture surface at higher magnification. In view of the fracture positions, the development of the fracture mode is easier to comprehend.

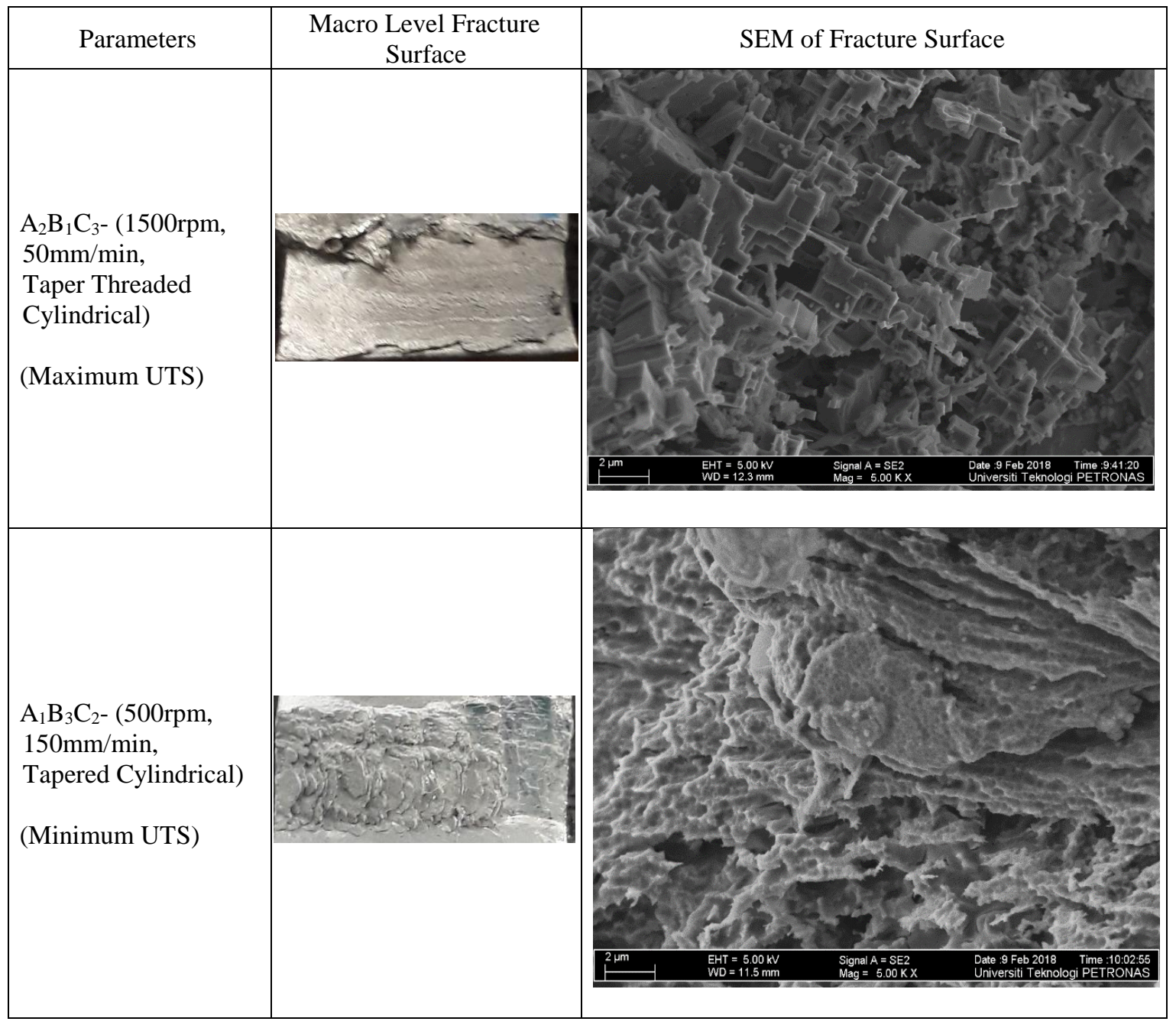

Figure 12. SEM images for fracture surface analysis.

The weld joint formed by $\mathrm{A}_{2} \mathrm{~B}_{1} \mathrm{C}_{3}$ process parameter displayed fine populated dimples focused towards the loading direction. Meanwhile, the weld joint formed by $\mathrm{A}_{1} \mathrm{~B}_{3} \mathrm{C}_{2}$ process parameter displayed both few flat featureless surfaces 
and fine dimples. A reduced amount of uneven and great precipitates volume fraction in the UFSW joints leads to further nucleation locations, and thus fine populated dimples are determined. Albeit both the weld joints exhibited ductile characteristics, the $A_{2} B_{1} C_{3}$ is fractured in more ductile mode compared to the $A_{1} B_{3} C_{2}$. The dimple's size and depth in the rupture surface of the $A_{2} B_{1} C_{3}$ weld joint is different compared to the $A_{1} B_{3} C_{2}$ weld joint. The dimples in the fracture surface of the $\mathrm{A}_{2} \mathrm{~B}_{1} \mathrm{C}_{3}$ weld joint are smaller and even, besides identified secondary cracks and quasi-cleavage planes in few positions. Similarly, it is also able to determine that the dimple elements in both the joints signifies the reduction of plastic deformation level using UFSW technique.

\section{CONCLUSION}

The influence of various parameters on the mechanical properties of the underwater friction stir welded joints of AA5052 were investigated and deliberated in detail. The conclusions drawn from this research are presented as follows:

1. UFSW can utilize to improve the mechanical properties of the weld joint. A maximum UTS value of $222.07 \mathrm{MPa}$ is attained (Joint efficiency: $97.4 \%$ of the BM) with a gauge elongation of $14.78 \%$ from the process parameter of $\mathrm{A}_{2} \mathrm{~B}_{1} \mathrm{C}_{3}$. The UTS and elongation value obtained by UFSW is about $8.4 \%$ and $1.7 \%$, correspondingly highercompared to the normal FSW joint. The reason for the improvement for strength in the joint is the integral cooling effect of water.

2. The microhardness distribution of the joints exhibited an uneven distribution of micro-hardness values throughout the weld line, besides yielded greater hardness value at the SZ compared to the BM. A maximum value of hardness as $300 \mathrm{HV}$ is yield by parameter of $\mathrm{A}_{2} \mathrm{~B}_{1} \mathrm{C}_{3}$ which obtained in the middle of the SZ, near advancing side (AS), is remarkably greater than that of its $\mathrm{BM}$ (77\% greater than the $\mathrm{BM})$. Joint hardness on the AS is higher compared to the RS, in most conditions.

3. Most of the UFSW joint tends to fracture at RS owing to limited tensile strain in the TMAZ of both sides of weld zone. Those weld joints that fractured at $\mathrm{AS}\left(\mathrm{A}_{2} \mathrm{~B}_{1} \mathrm{C}_{1}, \mathrm{~A}_{1} \mathrm{~B}_{1} \mathrm{C}_{2}, \mathrm{~A}_{1} \mathrm{~B}_{2} \mathrm{C}_{2}, \mathrm{~A}_{2} \mathrm{~B}_{1} \mathrm{C}_{2}, \mathrm{~A}_{2} \mathrm{~B}_{2} \mathrm{C}_{2}\right.$ and $\left.\mathrm{A}_{1} \mathrm{~B}_{1} \mathrm{C}_{3}\right)$ are exposed to inadequate amount of material flow and heat which attained by lower tool welding speed and presented poor tensile value. Most of the fracture locations are found on the TMAZ adjacent to the WNZ because of bigger grain sizes and affected the tensile properties of the joints. In process parameters of $A_{1} B_{1} C_{3}, A_{1} B_{2} C_{3}$ and $A_{1} B_{3} C_{3}$, the precipitate weakening level is increased at the WNZ of the joint as strain hardening of the low-density dislocations is insufficient to improve the strength loss and fractured at WNZ.

4. The mechanical properties of the weld joints are mainly reliant upon the process parameters. The controlling of heat input and microstructural evolutions is determined as the inherent reason for the strength enhancement by UFSW technique. Lower the heat input and time the stirring tool spent on the weld joint, the smaller the grain size, which leads to increase the tensile properties and micro-hardness.

\section{ACKNOWLEDGMENT}

This research is supported by the Ministry of Higher Education (MOHE) Malaysia under Fundamental Research Grant Scheme (FRGS) Ref. No. FRGS/1//2015/TK03/UTP/02/6.

\section{REFERENCES}

[1] Holt JM, Ho CY. Technical Ed. West Lafayette, IN, CINDAS/Purdue University 1996.

[2] Zhang H, Liu H. Characteristics and formation mechanisms of welding defects in underwater friction stir welded aluminum alloy. Metallography, Microstructure and Analysis. 2012;269-281.

[3] Pedapati SR, Paramaguru D, Awang M. Microhardness and microstructural studies on underwater friction stir welding of 5052 aluminum alloy. ASME International Mechanical Engineering Congress and Exposition. Advanced Manufacturing 2017;2:16.

[4] Fratini L, Buffa G, Shivpuri R. In-process heat treatments to improve FS-welded butt joints. The International Journal of Advanced Manufacturing Technology, 2009;43: 664-670.

[5] Zhao Y, Wang Q, Chen H, Yan K. Microstructure and mechanical properties of spray formed 7055 aluminum alloy by underwater friction stir welding. Materials and Design 2014;56:725-730.

[6] Zhang H, Liu H, Yu L. Effect of water cooling on the performances of friction stir welding heat-affected zone. Journal of Materials Engineering and Performance. 2012;21(7):1182-1187.

[7] Liu H, Zhang H, Yu L. Effect of welding speed on microstructures and mechanical properties of underwater friction stir welded 2219 aluminum alloy. Materials and Design. 2011; 32:1548-1553.

[8] Kishta EE, Darras B. Experimental investigation of underwater friction-stir welding of 5083 marine-grade aluminum alloy. Proc IMechE Part B: Journal of Engineering Manufacture. 2014; 8-16.

[9] Sabdin SD, Hussein NIS, Sued MK, Ayob MS, Rahim MAS, Fadzil M. Effects of cold arc welding parameters on the tensile strengths of high strength steel plate investigated using the Taguchi approach. Journal of Mechanical Engineering and Sciences. 2019;13(2):4846-4856.

[10] Standard test methods for tension testing of metallic materials. West Conshohocken, PA: ASTM International 2013. 
[11] Zipperian D. Metallographic Handbook. Tucson, Arizona, USA: PACE Technologies 2011.

[12] Hofmann D, Vecchio K. Submerged friction stir processing (SFSP): An improved method for creating ultra-fine-grained bulk materials. Materials Science and Engineering A. 2005;402:234-241.

[13] Kaushik N, Singhal S, Rajesh R, Gahlot P, Tripathi BN. Experimental investigations of friction stir welded AA6063 aluminum matrix composite. Journal of Mechanical Engineering and Sciences. 2018;12(4):4127-4140.

[14] Yan Y, Zhang DT, Qiu C, Zhang W. Dissimilar friction stir welding between 5052 aluminum alloy and AZ31 magnesium alloy. Transactions of Nonferrous Metals Society of China. 2010; 20(2): 619-623.

[15] Kwon YJ, Shim SB, Park DH. Friction stir welding of 5052 aluminum alloy plates. Transactions of Nonferrous Metals Society of China. 2009; 19(1):23-27.

[16] Sree Sabari S, Malarvizhi S, Balasubramanian V. Influence of tool travel speed on tensile properties of underwater friction stir welded high strength armour grade aluminium alloy joints. Journal of Manufacturing Engineering. 2016; 11(2): 94-100.

[17] Liu HJ, Zhang HJ, Huang YX, Yu L. Mechanical properties of underwater friction stir welded 2219 aluminum alloy. Trans. Nonferrous. Met. Soc. China. 2010; 20:1387-1391.

[18] Chen Y, Feng J, Liu H. Precipitate evolution in friction stir welding of 2219-T6 aluminum alloys. Materials characterization. 2009; 60:1: 476-481.

[19] Upadhyay P, Reynolds A. Effects of thermal boundary conditions in friction stir welded AA7050-T7 sheets. Materials Science and Engineering A. 2010; 527: 1537-1543.

[20] Feng X, Liu H, Lippold J. Microstructure characterization of the stir zone of submerged friction stir processed aluminum alloy 2219. Materials Characterization 2013; 82(1):97- 102.

[21] Yan Y, Zhang DT, Qiu C, Zhang W. Dissimilar friction stir welding between 5052 aluminum alloy and AZ31 magnesium alloy. Transactions of Nonferrous Metals Society of China. 2010; 20:2:619-623.

[22] Adnan F, Sajuri Z, Omar MZ. Effect of uniaxial load on microstructure and mechanical properties of Thixo-joint AISI D2 tool steel. Journal of Mechanical Engineering and Sciences. 2019;13(2):5006 - 5020. 